\title{
Tornando-se gerente de enfermagem na imbricada e complexa fronteira das dimensões assistencial e gerencial
}

\section{Becoming nursing manager in the nested and complex border of caring and management dimensions}

\author{
Gabriela Marcellino de Melo Lanzoni ${ }^{1}$, Aline Lima Pestana Magalhães ${ }^{2}$, Veridiana Tavares Costa ${ }^{3}$,
} Alacoque Lorenzini Erdmann ${ }^{4}$, Selma Regina de Andrade ${ }^{5}$, Betina Hörner Schlindwein Meirelles ${ }^{6}$

\footnotetext{
${ }^{1}$ Enfermeira, Doutora em Enfermagem. Professor Adjunto do Departamento de Enfermagem (NFR) da Universidade Federal de Santa Catarina (UFSC). Florianópolis, SC, Brasil. E-mail: gabriela.lanzoni@ufsc.br.

${ }^{2}$ Enfermeira, Mestre em Enfermagem. Discente do Programa de Pós-Graduação em Enfermagem (PEN), nível Doutorado, da UFSC. Florianópolis, SC, Brasil. E-mail: aline.pestana84@gmail.com.

${ }^{3}$ Enfermeira, Mestre em Enfermagem. Discente do Programa de Pós-Graduação em Enfermagem (PEN), nível Doutorado, da UFSC. Florianópolis, SC, Brasil. E-mail: veritavarescosta@gmail.com.

${ }^{4}$ Enfermeira, Doutorado em Enfermagem. Professor Titular do NFR/UFSC. Florianópolis, SC, Brasil. E-mail: alacoque@newsite.com.br.

${ }^{5}$ Enfermeira, Doutorado em Enfermagem. Professor Adjunto do NFR/UFSC. Florianópolis, SC, Brasil. E-mail: selma.regina@ufsc.br.

${ }^{6}$ Enfermeira, Doutorado em Enfermagem. Professor Associado do NFR/UFSC. Florianópolis, SC, Brasil. E-mail: betina.hsm@ufsc.br.
}

\section{RESUMO}

Objetivou-se compreender a experiência de estar exercendo a gerência de unidades de internação médico-cirúrgica de um hospital geral, destacando o significado de ser gerente de enfermagem, com o intuito de qualificar e instrumentalizar os enfermeiros para a prática de gerenciamento do cuidado neste cenário. Trata-se de uma Grounded Theory, realizada de agosto/2010 a agosto/2012, mediante entrevistas com 19 participantes da equipe de enfermagem, distribuídos em 3 grupos amostrais. Da análise emergiu o fenômeno "Tornando-se gerente de enfermagem na imbricada e complexa fronteira da dimensão assistencial e gerencial". Para o exercício da gerência do cuidado, o enfermeiro utiliza os instrumentos de gestão como ferramentas essenciais, capacita-se teoricamente e aprimora, com base em sua vivência/experiência, habilidades profissionais e características pessoais. Conclui-se que a mobilização de competências para além do âmbito clínico faz-se necessária, possibilitando a utilização dos instrumentos de gestão para viabilizar o cuidado e potencializar os processos relacionais e interativos.

Descritores: Gerência; Enfermagem; Supervisão de Enfermagem; Unidades de Internação.

\section{ABSTRACT}

The study aimed to understand the experience of managing medical-surgical inpatient units in a general hospital, highlighting the meaning of being a nursing manager, with the intention to qualify and instrument nurses for caring management practice in this scenario. This is a Grounded Theory research, conducted from August 2010 to August 2012, through interviews with 19 participants from the nursing team, distributed in 3 sampling groups. From the analysis emerged the phenomenon "Becoming a nursing manager in the nested and complex border of caring and management dimension". To exercise caring management, nurses use management instruments as essential tools, they become capable theoretically and enhances, based on his experience, professional skills and personal characteristics. We conclude that competency mobilization beyond the clinical aspect is needed; allowing the use of management instruments to make caring viable and to improve relational and interactive processes.

Descriptors: Management; Nursing; Nursing, Supervisory; Inpatient Care Units. 


\section{INTRODUÇÃO}

A profissionalização do trabalho da enfermagem destaca o enfermeiro como um dos responsáveis pelas questões administrativas nas instituições de saúde. Este âmbito de atuação muitas vezes colabora para que o profissional se afaste do cuidado direto, fato que traz divergência no que se refere à compreensão da atividade gerencial do enfermeiro ${ }^{(1-2)}$.

A prática de gerenciar está vinculada à administração da assistência, equipe e prestação de cuidados $^{(3)}$. Em contrapartida, as dimensões entre o assistir e o gerenciar, apesar de se complementarem, evidenciam que há enfermeiros com bom desenvolvimento na assistência, porém com fragilidades na atividade de gerência ou vice$\operatorname{versa}^{(4)}$.

A gerência do cuidado em unidades de internação hospitalares apresenta, como desafio aos enfermeiros, a prestação do cuidado, o trabalho em equipe multiprofissional e intersetorial, ao considerar as ações e relações que se tecem numa rede complexa. Entretanto, a prática profissional reproduz uma divisão técnica do seu trabalho, separando as tarefas gerenciais daquelas relacionadas à assistência direta ao paciente ${ }^{(3)}$.

A carência de clareza no que se refere à função de gerente ou líder ${ }^{(5)}$ pode limitar a prática de gerenciamento dos enfermeiros, visto que é preciso conhecer aquilo que se vai desenvolver, para evitar fragmentações das ações e fragilidade no desempenho ${ }^{(6)}$, uma vez que a liderança tem sido considerada um indicador de qualidade na prática de gerência do cuidado $^{(7)}$. Ainda, fatores como a falta de suporte da instituição e aspectos de liderança pouco desenvolvidos podem ser relacionadas à intenção de deixar a posição de gerente, embora não se tenha muita clareza dos motivos de retenção no cargo, por ser um fenômeno multifatorial e não possuir robusta literatura sobre o tema ${ }^{(8)}$. No Brasil, existe ainda a suposição de que qualquer profissional sabe gerir e que a administração se aprende na prática. São poucos os gestores ou gerentes que possuem formação específica, com apreensão de conhecimentos e habilidades próprias da gestão, entre elas: liderar grupos, favorecer a motivação e contribuir para a eficácia e efetividade das organizações e melhoria da qualidade de vida das pessoas no trabalho ${ }^{(9)}$.

A gestão de conflitos, que integra o processo de trabalho gerencial dos enfermeiros, deve ser realizada de modo a evitar o rompimento do trabalho em equipe, o que limitaria ainda mais a prática de gerenciamento dos enfermeiros $^{(3)}$. Recente revisão da literatura sobre a rotatividade na enfermagem identificou que gerentes influenciam diretamente na satisfação e na retenção de funcionários da sua equipe e que as consequências, neste âmbito, estão atreladas à baixa qualidade do cuidado oferecido e aumento de custos para as instituições de saúde ${ }^{(10)}$.

Nas unidades de internação médico-cirúrgicas adulto, a clientela é diversa em relação às patologias e à complexidade assistencial $^{(11)}$, gerando demandas distintas e inesperadas para o enfermeiro. Neste sentido, entende-se que o enfermeiro deve estar preparado para coordenar a equipe de enfermagem e gerir com excelência o cuidado destinado ao paciente ${ }^{(4)}$. Modelos organizacionais de unidades de internação hospitalar classificados com bom desempenho pautam suas ações tendo como estratégia principal a qualidade do cuidado ao paciente ${ }^{(12)}$ visando fomentar relações intra e interprofissionais.

Diante do exposto e considerando que a prática de gerenciamento pode exigir o desenvolvimento e/ou esclarecimento de competências pertinentes à função exercida $^{(8)}$, questiona-se: Como se dá a experiência da dinâmica da gerência de enfermagem de unidades de internação médico-cirúrgica adulto nos seus processos relacionais e interativos? Qual o significado de ser gerente de enfermagem? Neste sentido, este estudo objetiva compreender a experiência de estar exercendo a gerência de unidades de internação médico-cirúrgica de um hospital geral, destacando o significado de ser gerente de enfermagem, com $o$ intuito de qualificar e 
instrumentalizar os enfermeiros para a prática de gerenciamento do cuidado neste cenário.

\section{METODOLOGIA}

Pesquisa que adotou como referencial metodológico a Teoria Fundamentada nos Dados (TFD), também chamada Grounded Theory, que tem como finalidade compreender a realidade a partir da percepção ou significado que certo contexto ou objeto tem para a pessoa, gerando conhecimentos, aumentando a compreensão e proporcionando um guia significativo para a ação ${ }^{(13)}$.

O estudo foi realizado em um hospital universitário da região Sul do Brasil, tendo como participantes os profissionais que integram a equipe de enfermagem das unidades de internação médica e cirúrgica.

A coleta de dados ocorreu no período de agosto de 2010 a agosto de 2012. O convite aos participantes foi realizado pessoalmente no local de trabalho com a apresentação do projeto de pesquisa. Caso o profissional demonstrasse interesse em participar do estudo, era agendado um segundo encontro para realização da entrevista.

A seleção dos participantes, por amostragem teórica, foi intencional, sendo o primeiro grupo amostral formado por cinco enfermeiras gerentes das unidades de internação, das quais duas atuavam na unidade de internação cirúrgica e três na de médica. Todas eram do sexo feminino, com tempo de experiência profissional na enfermagem entre sete a 23 anos e atuavam como gerentes de enfermagem de um a três anos. Somente uma enfermeira tinha formação específica em Gestão em Saúde e Enfermagem. A coleta de dados foi realizada por meio de entrevista aberta, a partir das questões: Como você experiência a dinâmica da gerência de enfermagem de unidades de internação médico-cirúrgica adulto? Qual o significado de exercer a gerência de enfermagem nessa unidade?

Durante a coleta e análise dos dados do primeiro grupo amostral (E1-E5), identificou-se a hipótese de que a gerência do cuidado é uma atribuição do enfermeiro gerente, bem como do enfermeiro assistencial, mas as demandas assistenciais da gerência de enfermagem são compartilhadas com a equipe de enfermagem. Desse modo, percebeu-se a necessidade de incluir no estudo os enfermeiros assistenciais e técnicos de enfermagem, pois esses atores contribuem significativamente com o processo de tornar-se gerente de enfermagem e gestor do cuidado. Assim, o segundo grupo amostral (E6-E14) foi constituído por nove enfermeiros, sendo cinco assistenciais e quatro ex-gerentes que atuavam como assistenciais nas unidades de internação de estudo. Para este grupo, utilizou-se como questão norteadora: Qual a interface do seu trabalho como enfermeira assistencial com a gerência do cuidado de enfermagem? Fale-me o que você compreende por gerência do cuidado. A hipótese gerada a partir da análise dos dados do segundo grupo amostral confirmou os achados do primeiro grupo, apontando que compete ao enfermeiro a gerência do cuidado de enfermagem, mas é necessário articular os diferentes profissionais da equipe que trabalham em colaboração, com intuito de atender diretamente as necessidades dos pacientes.

Sendo assim, foi composto o terceiro grupo amostral (E15-E19), formado por cinco técnicos de enfermagem, os quais foram indagados a responder as seguintes questões: Como o seu trabalho está relacionado com o processo de gerência de enfermagem? De que forma você participa da gerência do cuidado?

O tamanho da amostra foi determinado pela saturação teórica dos dados, processo no qual o pesquisador observa repetição de informações e ausência de novos dados relevantes para o estudo(13). Assim, obteve-se 19 participantes no total, sendo as entrevistas áudio-gravadas em meio digital e transcritas na íntegra para análise.

Os dados foram analisados, de modo simultâneo a coleta, seguindo as etapas da codificação aberta, axial e seletiva. $\mathrm{Na}$ codificação aberta, os dados foram analisados linha por linha com o objetivo de identificar 
cada ideia, de modo a formar os códigos preliminares. Em seguida, estes foram reunidos, por similaridades e diferenças, elaborando os códigos conceituais. $\mathrm{Na}$ codificação axial reagruparam-se os dados que foram separados na etapa anterior, visando relacionar categorias às suas subcategorias, no sentido de obter uma explicação mais clara e completa sobre o fenômeno. A codificação seletiva é a busca e desenvolvimento do fenômeno ou categoria central, em torno do qual giram todas as demais categorias ${ }^{(13)}$.

A pesquisa foi realizada após a aprovação pelo Comitê de Ética em Pesquisa com Seres Humanos da Universidade Federal de Santa Catarina, sob o protocolo n. 896/10, respeitando os preceitos éticos preconizados nas resoluções do Conselho Nacional de Saúde. Para garantir o anonimato dos participantes utilizaram-se pseudônimos iniciados pela letra "E”, seguido por número ordinal (E1 a E19).

\section{RESULTADOS}

Do processo analítico emergiram as seguintes categorias: "Gerência do cuidado como conceito", "Tornando-se gerente de enfermagem de unidade de internação", "Características necessárias para um gerente de enfermagem" que sustentam o fenômeno: Tornandose Gerente de enfermagem na imbricada e complexa fronteira das dimensões assistencial e gerencial.

\section{Gerência do cuidado como conceito}

Composta por duas subcategorias: "Diferenciando cuidado gerencial e cuidado assistencial" e "integrando gerência do cuidado e assistência". Ao se referir à gerência de enfermagem, os participantes enfatizaram a importância da relação do ser gerente de enfermagem e atividade de gerência do cuidado executada pelos membros da equipe de enfermagem. Revela, ainda, as múltiplas faces da gerência do cuidado, sendo cada uma delas pormenorizada e, posteriormente, vislumbradas como interdependentes, articuladas e dinâmicas.
Na primeira subcategoria, enfatiza-se que gerenciar a unidade e gerenciar o cuidado são ações distintas. Os participantes afirmam que o gerenciamento da unidade no dia a dia está vinculado à parte burocrática e à administração do setor. Entendem que o gerenciamento do setor exige muita atenção e dedicação, pois se não for realizado de forma adequada o gerenciamento do cuidado ficará comprometido. Já as demandas da assistência, como por exemplo, como será realizado o cuidado, o porquê e onde são vinculadas ao gerenciamento do cuidado, emerge da relação direta entre enfermeiro, equipe de enfermagem e paciente, sendo supervisionadas pela enfermeira gerente, como ilustram as seguintes falas:

Na minha cabeça eu não tenho essa divisão de gerência do cuidado e gerência administrativa ou gerência técnica. Eu acho que tudo o que a gente faz no setor é para o cuidado (E8).

Existe diferença! Tem dois focos! Mas, tu tens que interligá-los lá na frente! Porque senão tu não consegues fazer uma boa assistência, um bom cuidado (E12).

Os participantes informam que inúmeras vezes se inserem na gerência do cuidado emitindo opinião, buscando ter uma visão do que está acontecendo, com vistas a antecipar-se com relação às possíveis necessidades. Nesse sentido, as participantes percebemse no meio dessas duas dimensões do gerenciamento do cuidado, considerando-as intimamente interligadas, uma única unidade inseparável. Tal perspectiva faz com que não tenham dificuldades para compreender o cuidado como um todo, intensamente imbricado, não permitindo revelar o limite de ser uma enfermeira assistencial ou gerencial, como pode ser visto nos depoimentos a seguir:

Eu fico bem no meio, eu gerencio tanto um quanto o outro. É claro que, às vezes, pesa mais o gerenciamento do setor porque é a parte burocrática (E3). 
A gente consegue trabalhar em parceria porque a chefia aqui é uma chefia bastante ativa. Ela participa da passagem do plantão, ela se esforça para participar da visita aos pacientes. Então, apesar dela estar fazendo a parte burocrática naquele momento, ela está muito atenta para o cuidado (E10).

Assim, segundo os participantes, as enfermeiras gerenciais realizam um cuidado indireto, interagindo com a assistência, conhecendo os pacientes para organizar o trabalho e atuando como enfermeira assistencial quando há falta de funcionários, por exemplo.

\section{Tornando-se gerente de enfermagem de unidade de internação}

Esta categoria é composta por três subcategorias: "Motivos para aceitar o cargo", "Preferência pela dimensão assistencial" e "Questionando sua capacidade para o cargo" que sustentam o processo de formação do ser enfermeira gerente.

Os participantes percebem que a oportunidade de assumir a gerência da unidade surgiu repentinamente, e que aceitaram o cargo com a intenção de contribuir com o setor e com a equipe de saúde, sem que, no entanto, tivessem outra opção. Por esse motivo, avaliam que assumiram o cargo sem maturidade suficiente, embora considerem que com o passar do tempo e com a vivência nesta atividade tornam-se mais preparadas e qualificadas, como demonstram as declarações abaixo:

Quando eu entrei na chefia foi uma coisa muito imprevisível [...] Não acho que naquele momento eu tinha perfil, maturidade. E é o tipo de coisa que a gente vai adquirindo com o tempo, esse "feeling" para resolução dos problemas (E2).

Eu não fui escolhida para chefia. Eu fui remanejada para lá [unidade de internação], porque ela [a outra candidata à chefia] desistiu. E daí, outra professora disse: você tem um perfil melhor para chefia, troca com ela que será melhor (E9).
Fui novamente convidada para assumir a chefia (E7).

Embora estejam gostando de atuar como enfermeiras chefes/gerentes, algumas participantes entendem, ainda, que seriam mais felizes se atuassem no cuidado direto, pois preferem estar próximas do paciente e atuar na dimensão assistencial por se identificarem com esta atividade. Percebem que ser gestora é ser alvo de críticas e por não se sentirem atraídas pelas demandas gerenciais concebem como difícil e desafiador o processo de gerenciar a unidade, como apresentam as seguintes falas:

Não, até porque não é um tipo de coisa que seja gratificante [...] se eu estivesse na assistência seria tão mais fácil (E2).

A enfermeira tem papel muito burocrático. [...] ela tenta atender a todos, porque sempre a gente recorre ao enfermeiro [...]. Então, fica bem sobrecarregada. Mas, ela tenta administrar da melhor forma possível (E18).

Algumas gerentes de enfermagem questionam-se quanto à efetividade de seu trabalho, pois estão insatisfeitas com seu desempenho por não conseguirem suprir todas as demandas gerenciais.

\section{Características necessárias para um gerente de enfermagem}

Esta categoria é composta por duas subcategorias: "Características subjetivas" e "Utilização dos instrumentos de gestão" que revelam o ser gerente de enfermagem a partir de qualidades pessoais e suas ferramentas de trabalho.

Para os participantes a atuação democrática é fundamental, uma vez que estimula a comunicação e a valorização do saber da equipe. Embora acreditem que seja possível todos intervirem no gerenciamento, consideram a aplicação desse modelo de gestão trabalhosa, o que exige um senso de justiça apurado para cobrar melhores resultados, conforme a fala a seguir: 
É necessário ter senso de justiça, direitos e deveres iguais. [...] Assim, ser democrático é uma consequência (E3).

Percebem que para promover mudanças devem recorrer à persuasão e à capacidade de influenciar os demais membros da equipe, e para exercer sua liderança buscam fazer as atividades corretamente e dar o exemplo. Nesse sentido, acreditam ser identificadas como líderes da equipe, pois não têm dificuldades para comandar e direcionar algumas atividades. Ainda, acreditam possuir algumas qualidades que facilitam sua inserção na gerência (conhecimento técnico, comunicação, liderança, disciplina, organização e doação integral). Entendem que para atuar em cargos de grande responsabilidade é necessário, muitas vezes, trabalhar além da carga horária, levando para casa preocupações e tarefas do trabalho, conforme ilustra o depoimento: Conhecimento técnico, comunicação e espírito de liderança são as três coisas básicas para uma boa condução do grupo (E5).

Destacam que, apesar das dificuldades apresentadas no campo de trabalho, as relações profissionais devem ter humor, responsabilidade e respeito. Tais qualidades fortalecem o vínculo e permitem que o grupo trabalhe em harmonia. A flexibilidade e a maleabilidade também são citadas como importantes qualidades para atuar em grupo, sendo fundamentais para adequar o nível de exigência tanto sobre os funcionários, quanto consigo mesmas. Os participantes revelam que aprenderam a balancear a cobrança e a compreensão, uma vez que as pessoas são diferentes em atitudes e potencialidades. Nesse sentido, essa reflexão foi direcionada para o seu próprio trabalho gerencial, muitas vezes considerado invisível para a produção do cuidado direto, como descrevem as assertivas:

Eu vejo, que a chefia é bem maleável. Assim, todo mundo tem o poder de dar opinião e trocar informações (E15).
Eu nunca tive dificuldade de lidar com autoridade, por exemplo. [...] Quando não era possível negociar, eu mandei. Mandei mesmo, de cima para baixo (E8).

Com relação à utilização dos instrumentos gerenciais, a comunicação efetiva é considerada fundamental para uma boa gestão, sendo utilizada como uma estratégia de motivação e de troca de experiências. Utilizá-la de forma objetiva faz a diferença no alcance das metas e no estabelecimento de um clima amistoso, como apresenta o depoimento:

É efetiva a comunicação na unidade. [...] A gente tem uma boa comunicação e um bom relacionamento entre as equipes (E3).

As gerentes de enfermagem consideram importante o trabalho pautado no planejamento, apontando a implantação da metodologia da assistência de enfermagem como um instrumento necessário para a gestão do cuidado, conforme descrito nas falas:

Meu trabalho é tanto a parte de planejamento, como fazer a assistência, orientar, supervisionar (E3).

Para a prática do gerenciamento do cuidado, a gente tem a metodologia de assistência que ajuda nisso, como por exemplo, a prescrição de enfermagem (E14).

Os depoimentos supracitados destacam a sistematização da assistência de enfermagem, em especial, a prescrição de enfermagem, como um instrumento que permite avaliar o cuidado.

Outro instrumento de gestão utilizado pelas enfermeiras é a avaliação de desempenho dos funcionários da unidade, relatada como sendo uma atividade constante, destacando-se a necessidade de realizá-la sempre que necessário. Por esse motivo, as enfermeiras procuram realizar a avaliação o mais cedo possível, sempre que percebe uma dificuldade ou um 
erro, visando minimizar risco ou dano à saúde do paciente, conforme demonstrado no depoimento:

Nesse momento de avaliação não é muito fácil. Quanto mais tempo passa, mais difícil fica. Temos que fazer a intervenção o quanto antes, visando garantir um cuidado de qualidade (E5).

As falas das enfermeiras relacionam a avaliação de desempenho dos funcionários com a garantia da qualidade do cuidado. Isto implica que a enfermeira ao deixar de considerar alguma situação que necessite ser pontuada na avaliação de um funcionário, ela pode estar contribuindo para o fortalecimento de práticas não seguras aos pacientes e, por isso, destaca esta atividade como uma intervenção imediata.

A supervisão foi mencionada pelas enfermeiras como outro instrumento de gestão que integra o gerenciamento do cuidado, destacando a supervisão dos funcionários e do cuidado realizado, conforme evidenciado no depoimento abaixo:

A parte da supervisão também, que faz parte do gerenciamento do cuidado, tanto a supervisão dos funcionários, quanto a supervisão do cuidado que foi realizado. Então, eu acho isso bem importante (E12).

As enfermeiras associam a observação das ações dos funcionários como sendo uma atividade que permite conhecer a equipe de enfermagem e fortalecer a supervisão, permitindo maior controle do cuidado e/ou assistência. Isso pode ser ratificado no depoimento:

A observação entra em tudo [...] eu acho que o principal é observar. Assim, estás atenta ao que está acontecendo e conhecerás os profissionais que estão trabalhando contigo (E7).

Outras atividades mencionadas pelas participantes, como parte do exercício da gerência das enfermeiras na unidade de internação, incluem a articulação entre as práticas de ensino e pesquisa e as orientações aos alunos em estágio supervisionado. Isso deve ser considerado como essencial para a gerência do cuidado, como pode ser ilustrado no depoimento a seguir:

A orientação dos alunos [...] a gente tem que estar orientando essa parte, gerenciando isso também (E12).

Ressalta-se que para haver mudança de pensamento no contexto das práticas de cuidado da enfermagem é essencial associar teoria e prática para o fortalecimento das ações gerenciais das enfermeiras.

\section{DISCUSSÃO}

A definição teórica do conceito de gerência do cuidado de enfermagem em cenários hospitalares vem despertando o interesse de pesquisadores, pois muitos enfermeiros, em sua prática profissional, percebem o administrar e o cuidar como processos separados. Além do mais consideram as atividades que compõem as partes destes como concomitantes e pouco prováveis de serem integrados ${ }^{(2)}$. Apesar de estar em busca de um novo modelo assistencial, a enfermagem permanece fragmentando o seu processo de trabalho, separando as tarefas gerenciais, consideradas indiretas, daquelas que envolvem o cuidado direto ${ }^{(3)}$. Neste sentido, o exercício gerencial dos enfermeiros suscita questões que acarretam desentendimentos e incompreensões ${ }^{(1)}$. Em contrapartida, defende-se o pressuposto de que o exercício profissional do enfermeiro constitui-se de diferentes dimensões, consideradas complementares e interdependentes, dentre as quais se destaca a dimensão assistencial e a gerencial $^{(4)}$.

Destaca-se que a literatura evidencia uma fragilidade na construção de um conceito sobre gerência do cuidado de enfermagem, que direcione a prática destes profissionais $^{(2)}$, implicando mudança na formação e no processo de trabalho dos gerentes de enfermagem. 
O trabalho do enfermeiro possui prioritariamente como marca e núcleo, o cuidado, e tem por finalidade a qualidade do cuidado, de modo que não pode haver separação entre a dimensão assistencial e a gerencial, pois haveria comprometimento da assistência realizada ${ }^{(4)}$.

As ações de cuidado direto e indireto ocorrem de forma integrada e articulada o que define a gerência do cuidado de enfermagem como sendo um processo dinâmico, situacional e sistêmico(2) $^{(2)}$ A dimensão organizacional do cuidado na contemporaneidade é paradoxal, uma vez que se quisermos alcançar resultados efetivos temos que priorizar os processos gerenciais, dentre eles, a liderança. O exercício de liderança pelo enfermeiro, além de fortalecer sua prática de gerência, principalmente, no que se refere ao gerenciamento de sua equipe, facilita a articulação das dimensões do processo de trabalho da enfermagem, constituídas pelas práticas assistencial e gerencial $^{(4,6)}$.

O desenvolvimento da liderança é considerado um processo continuo e, também, um indicador de satisfação no ambiente de trabalho. A prática de liderança necessita ser fortalecida, uma vez que os gerentes de enfermagem mencionam estarem pouco satisfeitos em seus ambientes de trabalho(7). Ainda, é importante destacar que a satisfação do paciente é utilizada como indicador de qualidade da assistência ${ }^{(14)}$.

Um estudo que avaliou o nível de satisfação dos pacientes em relação ao cuidado de enfermagem evidenciou que aspectos como a continuidade do cuidado e o trabalho em equipe foram considerados como requisitos avaliados positivamente pelos pacientes e que caracterizaram um alto grau de satisfação. Já aspectos relacionados ao pouco tempo que os enfermeiros despendem para atender diretamente os pacientes foram considerados motivo de insatisfação. O baixo grau de satisfação foi relacionado a inabilidade técnica, falta de pessoal e pouca autonomia da enfermagem ${ }^{(14)}$.

Para exercer a atividade gerencial, não basta apenas selecionar o gerente de enfermagem pelo histórico profissional e seu desempenho dentro da instituição, mas considerar se o enfermeiro tem a capacidade de lidar com as atribuições e responsabilidades do cargo, bem como conhecimento do processo de gestão em saúde ${ }^{(15-16)}$.

As organizações contemporâneas almejam gerentes com um perfil além do conhecimento científico, que possuam habilidades e competências capazes de detectar e analisar problemas organizacionais e propor alternativas de solução. Ainda é fundamental que o chefe tenha a capacidade de reconhecer e atender as necessidades da equipe, buscando proporcionar a harmonia no ambiente de trabalho. O cotidiano do gerente de uma unidade de internação é desafiador e estressante, envolve múltiplos entraves que desestimulam e desencorajam os enfermeiros a assumir este cargo. Outro fator que contribui para que o enfermeiro se esquive do cargo gerencial é a idealização de que o cuidado direto ao paciente tem mais valor que o exercício da chefia da unidade ${ }^{(17-18)}$.

É necessário que os enfermeiros gerentes reconheçam a complexidade deste cargo nos seus aspectos incertos, instáveis, inseguros, ilógicos, contraditórios, ambíguos, variáveis, aleatórios, indeterminados e outros mais que fogem da ordem, objetividade, certeza ou do determinado ${ }^{(18)}$.

Aliadas à complexa dinâmica da gerência de enfermagem, a sobrecarga de trabalho e a alta rotatividade da equipe limitam a implementação dessas práticas de forma articulada. Um estudo realizado sobre as características dos enfermeiros líderes em hospitais dos Estados Unidos evidenciou um aumento na carga horária de trabalho desses profissionais ao longo do tempo ${ }^{(19)}$. Outro estudo realizado na Holanda evidenciou que a alta rotatividade dos enfermeiros é um problema delicado, em que o gerente de enfermagem deve despender esforços para identificar os determinantes desta situação, bem como elaborar estratégias para resolução ${ }^{(20)}$. Desta forma, os gerentes de enfermagem, através de suas habilidades de liderança, devem garantir 
condições de trabalho favoráveis, com consequente satisfação e permanência da equipe.

A liderança com ênfase nas ações democráticas, o poder de comunicação e o senso de justiça, foram consideradas neste estudo como características subjetivas inerentes ao gerente de enfermagem. No Chile, uma das responsabilidades apontadas no exercício da enfermagem é a gerência do cuidado, a qual envolve uma série de competências e habilidades, dentre elas, a comunicação, informação e conhecimento para assim tomar as decisões corretas nesse âmbito ${ }^{(21)}$. Corroborando com essa evidência, um estudo realizado sobre o perfil gerencial de enfermeiros que atuam em um hospital público federal de ensino, destacou que essas características são relevantes ${ }^{(22)}$. Em outro estudo desenvolvido no Rio de Janeiro foi ressaltado que a experiência e maturidade profissional, bem como a capacidade de planejamento, organização, coordenação e direção são necessários para o exercício da gerência ${ }^{(18)}$.

Atuar com bom humor, responsabilidade, respeito, maleabilidade e flexibilidade, na gerência de enfermagem pode minimizar os conflitos existentes entre o enfermeiro gerente e a equipe assistencial ${ }^{(23)}$. A criatividade por parte dos enfermeiros, nos processos decisórios, adequando os recursos materiais e humanos no intuito de planejar uma assistência de qualidade ${ }^{(3)}$ pode se fazer necessária, como também a presença de práticas educativas voltadas para os trabalhadores de enfermagem e pacientes ${ }^{(4)}$.

A presente pesquisa evidenciou que o trabalho das enfermeiras gerentes encontra-se pautado no planejamento das atividades. Esta prática gerencial é considerada pelos enfermeiros de organizações hospitalares como uma estratégia de gestão fundamental para o desenvolvimento da liderança e essencial para transições de liderança suaves ${ }^{(19)}$. Assim, o planejamento das ações no âmbito do exercício do enfermeiro gerente implica avaliação constante de todo o sistema de produção da organização hospitalar. Nesta ótica, tal ferramenta de gestão pode facilitar a detecção de falhas nos processos de cuidado, possibilitando uma visão estratégica diferenciada dentro das organizações ${ }^{(22)}$.

Dentre as ferramentas de gestão, a SAE Sistematização da Assistência de Enfermagem é considerada uma ferramenta de avaliação da qualidade que possibilita aos enfermeiros domínio do seu processo de trabalho, avaliando suas ações, favorecendo a organização da assistência prestada e, assim, retroalimentando a si mesma ${ }^{(24)}$. Também, a implementação de registros eletrônicos de saúde em hospitais é considerada um desafio para a prática dos enfermeiros gerentes e esta tecnologia pode proporcionar melhorias na qualidade dos serviços ${ }^{(19)}$.

As atividades de supervisão, controle e avaliação, consideradas como múltiplas dimensões da gestão, concretizam-se como as melhores práticas do enfermeiro gestor $^{(25)}$. Tais atividades também foram destacadas pelas enfermeiras gerentes, no presente estudo, como instrumentos relevantes para a gerência do cuidado. Isso demonstra que esses profissionais estão em busca da adoção das melhores práticas para proporcionar maior segurança e qualidade no cuidado.

A literatura evidencia que uma melhor definição teórica e apreensão, pelos enfermeiros, sobre o conceito de gerência do cuidado de enfermagem; o desenvolvimento da liderança; e a identificação de determinantes da alta rotatividade da equipe são temas que, além de destacados na literatura nacional e, principalmente, internacional constituem desafios no contexto da prática de gerência do cuidado de enfermagem nas unidades de internação ${ }^{(2,7,11,20)}$.

Espera-se que os enfermeiros gerentes enfrentem tais desafios instrumentalizando-se para a reflexão de suas práticas. Isto implica a melhoria da assistência e avanço para a excelência das práticas de gerência do cuidado.

\section{CONSIDERAÇÕES FINAIS}

O fenômeno "Tornando-se gerente de enfermagem na imbricada e complexa fronteira da dimensão 
assistencial e gerencial", apresenta as principais contribuições e desafios enfrentados pelos gerentes de enfermagem para a gestão do cuidado, sendo sustentado pela inter-relação das categorias: "Gerência do cuidado como conceito", "Tornando-se gerente de enfermagem de unidade de internação", "Características necessárias para um gerente de enfermagem".

A gerência do cuidado de enfermagem apresenta-se como uma unidade complexa que compreende a diversidade das atividades administrativas e da assistência como uma imbricada rede de ações do enfermeiro gerente. Ser enfermeiro gerente de unidade de internação revelou-se como um desafio para os profissionais, que não visavam atuar neste cargo. Esses enfermeiros identificaram características subjetivas, como a flexibilidade, bom humor, senso de justiça, liderança, comunicação efetiva, atuação democrática, e a utilização dos instrumentos de gestão, como ferramentas elementares para uma atuação que viabiliza o cuidado efetivo nos seus processos relacionais e interativos. Além da utilização destas ferramentas, o profissional com potencial para a área gerencial requer desenvolvimento, capacitação e ser gradativamente desafiado a aplicar essas novas competências. Esta complexidade da gerência de enfermagem permeia toda a ação profissional, frente às relações e interações que se estabelecem na complexa rede de cuidado e de gestão em saúde.

As unidades de internação médico-cirúrgicas adulto são complexas, especializadas e atendem uma clientela com diversas patologias e com múltiplas necessidades de cuidado. Tal situação requer dos enfermeiros conhecimentos, habilidades e atitudes para a compreensão do processo saúde-doença em uma dimensão ampliada, que favoreça o cuidado resolutivo. A mobilização de competências para além do âmbito clínico faz-se necessária, possibilitando o enfermeiro assumir a sua função de gerente do cuidado de enfermagem.

Os resultados deste estudo mostram a experiência de profissionais da equipe de enfermagem do turno diurno das unidades médico-cirúrgicas de um hospital geral, cujas habilidades gerenciais foram desenvolvidas com o passar do tempo e com o interesse do profissional enfermeiro, em especial o gerente de enfermagem. Tal desenvolvimento implica busca de conhecimentos teóricos de forma individual e com a realização de capacitações e especializações na área de administração/gestão em enfermagem.

Tornar o exercício da gerência algo atrativo e gratificante para os enfermeiros constitui-se em um desafio, pois muitas vezes o processo de gerenciar a unidade ainda é desestimulante diante das demandas, dos resultados a longo prazo e do pouco suporte recebido dos níveis superiores de administração das instituições de saúde. Além disso, é importante fomentar discussões no contexto educacional, ainda no processo de formação do enfermeiro, a fim de facilitar e despertar o desejo para o exercício da gerência na prática profissional.

Aponta-se como necessidade, para futuras investigações, abordar os elementos que podem contribuir para a atuação do gerente de enfermagem, visando reconhecer amplamente os fatores que intervêm e que geram repercussões no trabalho em saúde, bem como na segurança, satisfação do profissional e qualidade assistencial.

2. Christovam BP, Porto IS, Oliveira DC. Nursing care management in hospital settings: the building of a construct. Rev. esc. enferm. USP [Internet]. 2012 [acesso em: 30 jun 2015];46(3):734-41. Disponível em: http://dx.doi.org/10.1590/S008062342012000300028.

3. Martins JT, Robazzi MLCC, Marziale MHP, Garanhani ML, Haddad MCL. Significados do gerenciamento de unidade de terapia 
intensiva para o enfermeiro. Rev. Gaúcha Enferm. [Internet]. 2009 [acesso em: 30 jun 2015];30(1):113-9. Disponível em:

http://www.seer.ufrgs.br/RevistaGauchadeEnfermagem/article/vi ew/8883.

4. Hausmann M, Peduzzi M. Articulação entre as dimensões gerencial e assistencial do processo de trabalho do enfermeiro. Texto contexto - enferm. [Internet]. 2009 [acesso em: 30 jun 2015];18(2):258-65. Disponível em:

http://dx.doi.org/10.1590/S0104-07072009000200008. 5. Strapasson MR, Medeiros CRG. Liderança transformacional na enfermagem. Rev. bras. enferm. [Internet]. 2009 [acesso em: 30 jun 2015];62(2):228-33. Disponível em:

http://dx.doi.org/10.1590/S0034-71672009000200009.

6. Paula GF, Figueiredo ML, Camargo FC, Iwamoto HH, Caixeta CRCB. Concepções de liderança entre enfermeiros assistenciais de um hospital do Norte de Minas Gerais. Rev. Eletr. Enf. [Internet]. 2012 [acesso em: 30 jun 2015];14(4):821-30. Disponível em: http://dx.doi.org/10.5216/ree.v14i4.15102.

7. Newman C, Patterson K, Clark G. Evaluation of a support and challenge framework for nursing managers in correctional and forensic health. J Nurs Manag [Internet]. 2015 [acesso em: 30 jun 2015];23(1):118-27. Disponível em:

http://dx.doi.org/10.1111/jonm.12099.

8. Brown P, Fraser K, Wong CA, Muise M, Cummings G. Factors influencing intentions to stay and retention of nurse managers: a systematic review. J Nurs Manag [Internet]. 2013 [acesso em: 3 jun 2015];21(3):459-72. Disponível em:

http://dx.doi.org/10.1111/j.1365-2834.2012.01352.x. 9. Amaral AEEHB. Gestão de Pessoas. In: Ibañez N, Elias PEM, Seixas PHD, orgs. Política e Gestão Pública em Saúde. São Paulo: Hucitec Editora: Cealag; 2011. p. 553-85.

10. Hayes LJ, O'Brien-Pallas L, Duffield C, Shamian J, Buchan J, Hughes $F$, et al. Nurse turnover: a literature review - an update. Int J Nurs Stud [Internet]. 2012 [acesso em: 30 jun 2015];49(7):887905. Disponível em:

http://dx.doi.org/10.1016/j.ijnurstu.2011.10.001.

11. Araújo VB, Perroca MG, Jericó MC. Variability in the complexity of patient's nursing care needs. Rev Lat Am Enfermagem [Internet]. 2009 [acesso em: 30 jun 2015];17(1):34-9. Disponível em: http://dx.doi.org/10.1590/S0104-11692009000100006. 12. Mclntosh N, Meterko M, Burgess JF, Restuccia JD, Kartha A, Kaboli $P$, et al. Organizational predictors of coordination in inpatient medicine. Health Care Manage Rev [Internet]. 2014 [acesso em: 30 jun 2015];39(4):279-92. Disponível em: http://dx.doi.org/10.1097/HMR.0000000000000004. 13. Strauss A, Corbin J. Pesquisa Qualitativa: técnicas e procedimentos para o desenvolvimento de teoria fundamentada. 2a ed. Porto Alegre: Artmed; 2008.

14. Alasad JA, Ahmad MM. Patients' satisfaction with nursing care in Jordan. Int J Health Care Qual Assur [Internet]. 2003 [acesso em: 30 jun 2015];16(6):279-85. Disponível em:

http://dx.doi.org/10.1108/09526860310495660.

15. Furukawa PO, Cunha ICKO. Profile and competencies of nurse managers at accredited hospitals. Rev Lat Am Enfermagem [Internet]. 2011 [acesso em: 30 jun 2015];19(1):106-14. Disponível em: http://dx.doi.org/10.1590/S0104-11692011000100015.

16. Aarestrup C, Tavares CMM. A formação do enfermeiro e a gestão do sistema de saúde. Rev. Eletr. Enf. [Internet]. 2008 [acesso em: 30 jun 2015];10(1):228-234. Disponível em: http://www.fen.ufg.br/revista/v10/n1/v10n1a21.htm.
17. Baker S, Marshburn DM, Crickmore KD, Rose SB, Dutton K, Hudson PC. What do you do? Perceptions of nurse manager responsibilities. Nurs Manag [Internet]. 2012 [acesso em: 30 jun 2015];43(12):24-9. Disponível em:

http://dx.doi.org/10.1097/01.NUMA.0000422890.99334.21.

18. Moura GMSS, Inchauspe JAF, Dall'Agnol CM, Magalhães AMM, Hoffmeister LV. Expectations of the nursing staff in relationship to leadership. Acta Paul Enferm [Internet]. 2013 [acesso em: 30 jun 2015];26(2):198-204. Disponível em:

http://dx.doi.org/10.1590/S0103-21002013000200015.

19. Westphal JA. Characteristics of nurse leaders in hospitals in the USA from 1992 to 2008. J Nurs Manag [Internet]. 2012 [acesso em: 30 jun 2015];20(7):928-37. Disponível em:

http://dx.doi.org/10.1111/j.1365-2834.2012.01403.x.

20. Homburg V, van der Heijden B, Valkenburg L. Why do nurses change jobs? An empirical study on determinants of specific nurses' post-exit destinations. J Nurs Manag [Internet]. 2013 [acesso em: 30 jun 2015];21(6):817-26. Disponível em: http://dx.doi.org/10.1111/jonm.12142.

21. Estefo Agüero S, Paravic Klijn T. Enfermería en el rol de gestora de los cuidados. Cienc y enfermería [Internet]. 2010 [acesso em: 30 jun 2015];16(3):33-9. Disponível em: http://dx.doi.org/10.4067/S0717-95532010000300005.

22. Giordani JN, Bisogno SBC, Silva LAA. Perception of nurses regarding management activities for user assistance. Acta Paul Enferm [Internet]. 2012 [acesso em: 30 jun 2015];25(4):511-6. Disponível em: http://dx.doi.org/10.1590/S010321002012000400005.

23. Guerra ST, Prochnow AG, Trevizan MA, Guido LA. Conflict in nursing management in the hospital context. Rev Lat Am Enfermagem [Internet]. 2011 [acesso em: 30 jun 2015];19(2):3629. Disponível em: http://dx.doi.org/10.1590/S010411692011000200019.

24. Conceição VM, Nogueira Junior C, Araújo JS, Monteiro MOP. A gestão da qualidade e a Sistematização da Assistência de Enfermagem: uma revisão sobre sistemas de informação. R. Enferm. Cent. O. Min. [Internet]. 2012 [acesso em: 30 jun 2015];2(1):124-33. Disponível em:

http://www.seer.ufsj.edu.br/index.php/recom/article/view/169. 25. Costa, VT, Meirelles BHS, Erdmann AL. Best practice of nurse managers in risk management. Rev Lat Am Enfermagem [Internet]. 2011 [acesso em: 30 jun 2015];21(5):1165-71. Disponível em: http://dx.doi.org/10.1590/S0104-11692013000500021.

Recebido: 25/04/2014.

Aceito: 02/02/2015.

Publicado: 30/06/2015. 